\title{
Undefined Oncological Risk of Fat Grafting Procedures in the Breast
}

(D) Charoo Piplani ${ }^{1}$, (1) Duneska D. Obando², (1) Andrea Ramírez², (1) Natalia Cátala 3 , (1) John P. Garcia

(1) Ricardo A. Torres-Guzman ${ }^{4}$

${ }^{1}$ Clara Swain Mission Hospital, Bareilly, India

${ }^{2}$ Universidad del Rosario, Bogotá, Colombia

${ }^{3}$ Medical Sciences Campus, University of Puerto Rico, San Juan, Puerto Rico

${ }^{4}$ Division of Plastic Surgery, Mayo Clinic, Jacksonville, Florida, USA

Cite this article as: Piplani C, Obando DD, Ramírez A, Cátala N, Garcia JP, Torres-Guzman RA. Undefined Oncological Risk of Fat Grafting Procedures in the Breast. Eur J Breast Health 2022; 18(1): 105-106

Dear Editor,

Over time, radiation-induced changes in the skin and soft tissues result in deformities such as induration, decreased elasticity and mobility, atrophy, xerosis, pigmentation, and local tissue changes (1). Chronic radiation-induced injury leads to both cosmetic and functional impairment (1). Management is aimed at reversing these changes by use of radioprotective agents, tissue debridement, skin grafting, local and free vascularized flaps, and more recently, adipose tissue grafting (2). The concept of fat grafting was first introduced in 1893 by German plastic surgeon Gustav Neuber. Based on current evidence, Kenny et al. (1) described its benefits in the breast, extremities, orbit, head and neck.

An important question raised by them was the undefined risk of oncological recurrence resulting from fat grafting into the irradiated breast tissue (1). The relationship between fat grafts and breast cancer cells has been explored in the past. One of the most extensive patient series was published by Petit et al. (3) in 2011, consisting of a multicenter analysis of 513 patients undergoing fat grafting after breast cancer. With an average follow-up time of 19.2 months, the study revealed a local recurrence rate of $2.4 \%$ (1.5\%/year) and an overall recurrence of $5.6 \%(3.6 \% /$ year). A higher locoregional recurrence rate was observed in carcinoma in situ patients compared to those with invasive cancer.

A retrospective study by Rigotti et al. (4), published data including 137 mastectomy patients (105 with infiltrating breast cancer and 31 with cancer in situ) between 1988 - 2009, with a three-year minimum follow-up period. Five patients (3.6\% of the overall population) were diagnosed with local recurrence post fat grafting compared to four patients (2.9\% of the overall population) between surgery and the first fat grafting procedure. It was concluded that fat grafting after mastectomy did not increase local oncological recurrence.

Basic science and clinical studies have provided contradictory data on these procedures' safety profiles, making it difficult to make a definitive claim about their oncologic safety. The primary concerns are the lack of an ideal control group for comparison, retrospective analysis by most publications, and inadequate follow-up. The lack of standardization of fat harvesting, processing, and technique further adds to the challenge. As proposed by Kenny et al (1), better animal models and a larger working group with a longer follow-up period can provide these answers. Additionally, we strongly feel that high-quality research focusing on irradiated tissue's oncological potential following fat grafting can provide a better clinical correlation.

We propose that basic science models be based on samples from the same patient as opposed to laboratory-stored cell lines. This can be done for individual case reports for better homology. Guidelines with a longer definite follow-up period and a strong control group must be accomplished. A definite wait time from previous procedures (if any), based on individual risk factors, must be implemented for any clinical trial in the field. The need for prospectively controlled long-term clinical trials must be encouraged. These measures will help answer these questions sooner and enable healthcare providers to safely use the fat grafting technique. 
Keywords: Breast cancer, breast reconstruction, fat grafting

Peer-review: Externally peer-reviewed.

\section{Authorship Contributions}

Concept: R.A.T.G.; Design: R.A.T.G.; Data Collection and/or Processing: C.P., D.D.O., A.R., N.C., J.P.G., R.A.T.G.; Analysis and/or Interpretation: C.P., D.D.O., A.R., N.C., J.P.G., R.A.T.G.; Literature Search: C.P., D.D.O., A.R., N.C., J.P.G., R.A.T.G.; Writing: C.P., D.D.O., A.R., N.C., J.P.G., R.A.T.G.

Conflict of Interest: No conflict of interest declared by the authors.

Financial Disclosure: The authors declare that this study received no financial disclosure.

\section{References}

1. Kenny EM, Egro FM, Ejaz A, Coleman SR, Greenberger JS, Rubin JP. Fat grafting in radiation-Induced soft-tissue injury: a narrative review of the clinical evidence and implications for future studies. Plast Reconstr Surg 2021; 147: 819-838. (PMID: 33776031) [CrossRef]
2. Akita S. Treatment of radiation injury. Adv Wound Care (New Rochelle) 2014; 3: 1-11. (PMID: 24761339) [CrossRef]

3. Petit JY, Lohsiriwat V, Clough KB, Sarfati I, Ihrai T, Rietjens M, et al. The oncologic outcome and immediate surgical complications of lipofilling in breast cancer patients: a multicenter study--Milan-Paris-Lyon experience of 646 lipofilling procedures. Plast Reconstr Surg 2011; 128: 341-346. Erratum in: Plast Reconstr Surg 2011; 128: 1317. (PMID: 21502905) [CrossRef]

4. Rigotti G, Marchi A, Stringhini P, Baroni G, Galiè M, Molino AM, et al. Determining the oncological risk of autologous lipoaspirate grafting for post-mastectomy breast reconstruction. Aesthetic Plast Surg 2010; 34: 475-480. (PMID: 20333521) [CrossRef] 